\section{Effect of intradialytic physical activity on the quality of life, biological \\ parameters and sleep in hemodialysis patients}

\author{
Mélanie Gallot ${ }^{1 *}$, Nathalie Rieth ${ }^{1 \#}$ and Alexandre Ganea ${ }^{2 \#}$ \\ 'Laboratoire CIAMS, Université d'Orléans-Université Paris Sud-Paris Saclay, Collégium Sciences et \\ Techniques- Pôle STAPSallée du Château 45100 Orléans, France \\ ${ }^{2}$ Centre Hospitalier Régional, Service de Néphrologie-Dialyse, 14 avenue de l'hôpital 45067 \\ Orléans, France \\ "Both of these senior authors contributed equally to this work
}

\section{Abstract}

Many side effects, in addition to those of the pathology itself, have occurred with hemodialysis treatment but existing literature have shown that physical activity is beneficial to hemodialysis patients. Nevertheless, our parameters have not been studied enough with a resistance training program. In our study we have observed the effect of a 12-week intradialytic resistance training program (TO vs T12) on the quality of life using the KDQOL-SF questionnaire, blood samples biological parameters and sleep using the Epworth scale and the International restless legs syndrome study group scale. The resistance training program consists of 3 sessions per week and involved lower extremities thanks to elastic band and soft ball. After the training program, the quality of life score trend to the increase at T12 compared to T0. Among the biological parameters, the only trend decrease observed was in the C-reactive protein and a trend increase was observed in urea at T12. Dialysis efficiency presented no changes and no significant results were observed for sleep. Some trends were observed as a result of our program. The type of exercise seems to have different effects on measured parameters. Nevertheless, exercise was beneficial to chronic hemodialysis patients and seemed to improve their health.

\section{More Information}

*Address for Correspondence: Mélanie Gallot, Laboratoire LIBM, Université Claude Bernard Lyon 1, 4 rue Raphaël Dubois, 69100 Villeurbanne, France, Tel: +33 6887800 21; Email: gallot.melanie@yahoo.fr

Submitted: 09 November 2019

Approved: 21 November 2019

Published: 22 November 2019

How to cite this article: Gallot M, Rieth N, Ganea A. Effect of intradialytic physical activity on the quality of life, biological parameters and sleep in hemodialysis patients. J Clini Nephrol. 2019; 3: 168-174.

\section{DOI: dx.doi.org/10.29328/journal.jcn.1001044}

Copyright: @ 2019 Gallot M, et al. This is an open access article distributed under the Creative Commons Attribution License, which permits unrestricted use, distribution, and reproduction in any medium, provided the original work is properly cited.

Keywords: Hemodialysis; Physical activity; Quality of life; Sleep; Biological parameters

Check for updates

\section{Introduction}

Hemodialysis is one of the renal replacement therapies for patients with chronic kidney diseases (CKD). Many side effects occur with both the pathology and the treatment, such as an increase in sedentary lifestyle, body composition modifications, a decrease in the quality of life, and sleep disturbances [1-3]. Dialysis patients are approximately $35 \%$ less active than healthy people; disease-related pathologies are therefore more prevalent in this ailing population [4]. 0 'Hare [1] showed that mortality in dialysis patients is $62 \%$ higher than in healthy people; the main cause of death being cardiovascular disease.

The dialysis patient's quality of life is therefore negatively affected. Perlman measured the quality of life with the SF36 questionnaire. Scores in patients with CKD were lower than those of the healthy population and higher than those of dialysis patients [5]. Moreover, $44 \%$ of CKD patients suffer from sleep disturbance and 30\% have restless legs syndrome [6].
In dialysis patients, the health status could be defined by some biological parameters such as urea, albumin, creatine or C-reactive protein (CRP) and by the dialysis efficiency [7]. The inflammatory marker, C-reactive protein (CRP), has shown a dose-response relationship to coronary heart disease [8]. As a reminder, cardiovascular diseases have been the main cause of death in hemodialysis patients [1]. Moreover, inflammation, and in particular CRP concentration, is associated with lower levels of physical activity in the dialysis population [9].

Many positive effects of physical activity are observed in hemodialysis patients using different training programs, for instance, an increase in physical capacities [10], a decrease in kidney disease-related pathologies [11], an improvement in the quality of life [3]. Guidelines for CKD patients were similar to the general aged population: aerobic training, resistance training and balance and flexibility exercises [12].

To our knowledge, few studies have carried out resistance 
training programs on hemodialysis patients only [13] and on our parameters. Therefore, the aim of our study was to evaluate the intradialytic resistance training program effects on chronic hemodialysis patients, on their quality of life, sleep and some biological parameters.

\section{Methods}

\section{Patients}

This study included patients from the Regional Hospital Center in Orleans (France) undertaking hemodialysis in two different dialysis units.

All patients selected were stable hemodialysis patients, dialyzed three times a week for a minimum duration of three months, aged at least 18 years and without medical contraindication to physical activity or collection of outcome measures.

A total of 35 patients were enrolled in the study and were fairly assigned to either a physical activity group (PA group) which performed a physical training program, or a control group (C group) which not by random draw realized by a biostatistician. Due to different causes, renal transplant, lack of interest of our study or medical problems, 23 patients fully completed the study (age: $58.5 \pm 13.8$ years): 17 patients in the PA group (age: $59.42 \pm 13.82$ years; Body Mass Index: 28.4 $\pm 6.1 \mathrm{~kg} / \mathrm{m}^{2}$ ) and 6 in the $C$ group (age: $60.71 \pm 10.32$ years; Body Mass Index: $24.1 \pm 4.4 \mathrm{~kg} / \mathrm{m}^{2}$ ). There was no significant difference in the age or the Body Mass Index between the two groups.

Ethical approval was obtained from both the CPP (Comité de Protection des Personnes) in Tours (France) and the ANSM (Agence nationale de sécurité du médicament et des produits de santé, France). Written informed consent was obtained from all patients.

\section{Study design}

Intervention: Physical training program consisted of 3 weekly intradialytic resistance sessions over a 12- week period. Each exercise session was supervised by a coach for the entire duration and performed during the first two hours of dialysis [11].

The resistance, applied with the use of a resistance band or a soft ball, involved the lower extremity muscles only due to fistula presence in the upper extremities. The exercise movements were the following: hip, knee and ankle flexion and extension; hip abduction and adduction; and ankle rotation.

A learning phase without materials was performed over a period of 1 to 4 weeks during the first month of physical training program. The resistance intensity, using the different possibilities of the resistance bands and soft balls, and the exercise intensity, characterized by the number of sets and repetitions, were based on Borg's scale of perceived exertion [14].

Outcome measures: All outcome measures-were collected at baseline (T0) and 12 weeks (T12) of the study in all patients.

Quality of life: The KDQOL-SF questionnaire was used for measuring the quality of life of patients with a kidney failure [15]. This self-administered questionnaire includes 79 items; 36 of which correspond to the SF-36 (Short-Form 36) questionnaire and 43 to the KDQOL (Kidney Disease Quality of Life) questionnaire.

The SF-36 questions evaluate 8 parameters: physical functioning; physical role limitation; bodily pain; general health perception; vitality; social functioning; emotional role limitation; and emotional well- being. The first four parameters correspond to the physical category and the four latter parameters represent the psychic category [16].

The KDQOL questions evaluate 11 parameters: dialysisrelated symptoms; adverse effect of kidney disease on lifestyle; burden of kidney disease on lifestyle; work status; cognitive function; social interactions; sexual function; sleep; social support; encouragement of dialysis staff; and treatment satisfaction [15].

A global score out of 100 points was calculated for the KDQOL-SF questionnaire, and equally for the KDQOL, SF and parameters. A score lower than 66.7/100 indicates a lower quality of life [17].

Biological parameters: Every month, blood samples were collected by nurses and analyzed by a laboratory. We observed the concentrations of urea $(\mathrm{g} / \mathrm{L})$, creatine $(\mathrm{mg} / \mathrm{L})$, albumin (g/L), and C Reactive-Protein or CRP (mg/L). We also observed the dialysis efficiency (Kt/V). All the biological parameters were taken at dialysis start and the $\mathrm{Kt} / \mathrm{V}$ at dialysis end.

Sleep: Two self-questionnaires were used to observe the importance of sleep disorders.

The Epworth scale allows the detection of pathological daytime sleepiness [18]. It contains 8 items scored from 0 (no risk of daytime sleepiness) to 3 (high risk of daytime sleepiness).

The International Restless Legs Syndrome Study Group scale (IRLSSG) evaluates the importance of restless legs syndrome during wakefulness and leg movements during sleep [19]. It contains 10 items with a scale from 0 (no symptoms) to 4 (high symptoms).

\section{Statistics}

Statistica 7.1 was used for statistical analysis. A Shapiro- 
Wilk test was used for each variable to observe their normality. A Student T-Test or a Mann-Whitney test was subsequently performed.

The data collected were presented in mean \pm SD. The significance was set as $p \leq 0.05$.

\section{Results}

\section{Quality of life}

The results of the KDQOL-SF and its two parts (KDQOL and SF-36) are presented in the figure 1.

For the PAgroup and the Cgroup, the scores of the KDQOL$\mathrm{SF}$ and the two parts presented no significant differences between $\mathrm{T} 0$ and $\mathrm{T} 12$.

No significant differences were observed between the two groups.

The results for the psychic SF-36 and the physic SF-36 are presented in the figure 2 .

For the PA group, the psychic SF-36 scores increased between T0 and T12 (59.2 \pm 20.4 vs $71.1 \pm 14.2, p<0.05)$.

Concerning the physic SF-36 scores, no significant differences were observed whatever the considered period.

Furthermore, for the $\mathrm{C}$ group, the scores of the two parts of

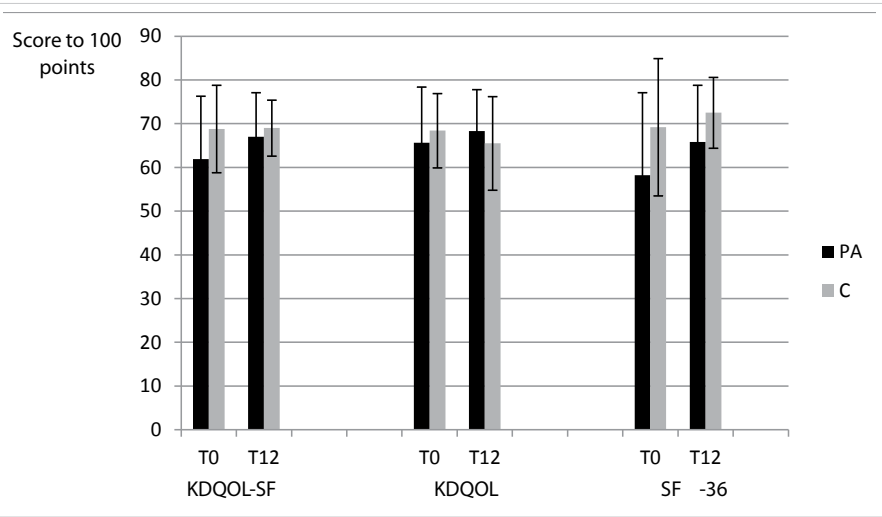

Figure 1: The results of the KDQOL-SF and its two parts (KDQOL and SF-36).

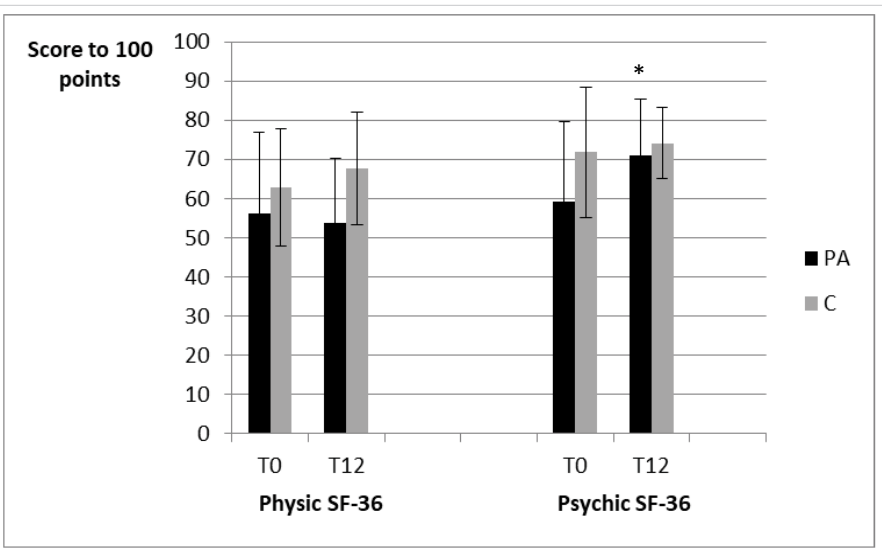

Figure 2: The results for the psychic SF-36 and the physic SF-36 the SF-36 questionnaire presented no significant differences between the beginning and the end of the study.

No significant differences were observed between the two groups.

The results for the 11 parameters of the KDQOL questionnaire are presented in the table 1.

For the PA group, we observed an increase in the dialysisrelated symptom score following the training program $(p<$ 0.05).

For the $\mathrm{C}$ group, concerning the adverse effect of kidney disease on lifestyle, we observed a decrease in the score at T12 as compared to T0 $(p<0.05)$.

With reference to the T12 period, we also noticed a higher score in the "encouragement of the dialysis staff" in the PA group, compared to the $\mathrm{C}$ group $(p<0.05)$.

The results for the 8 parameters of the SF-36 questionnaire are presented in the table 2 .

For the PA group, the emotional role limitation score was increased at the end as compared to the beginning of the physical training program $(p<0.05)$.

Table 1: The KDQOL parameters scores at the beginning (T0) and at the end (T12) of the study for both the physical activity group (PA) and the control group (C).

\begin{tabular}{|c|c|c|c|c|}
\hline & \multicolumn{2}{|c|}{ PA } & \multicolumn{2}{|c|}{ C } \\
\hline & TO & T12 & TO & T12 \\
\hline Dialysis-related symptoms & $69.5 \pm 13.9$ & $77.2 \pm 13.2^{*}$ & $75.9 \pm 14.9$ & $74.6 \pm 12.6$ \\
\hline $\begin{array}{l}\text { Adverse effect of kidney } \\
\text { disease on lifestyle }\end{array}$ & $50.9 \pm 17.6$ & $55.3 \pm 20.3$ & $60.4 \pm 9.5$ & $50 \pm 8.3^{*}$ \\
\hline $\begin{array}{c}\text { Burden of kidney disease } \\
\text { on lifestyle }\end{array}$ & $47.4 \pm 22.8$ & $48.5 \pm 20.9$ & $42.5 \pm 34.3$ & $56.2 \pm 23.4$ \\
\hline Work status & $30 \pm 41.4$ & $33.3 \pm 40.8$ & $12.5 \pm 25$ & $12.5 \pm 25$ \\
\hline Cognitive function & $79.2 \pm 24.9$ & $82.8 \pm 17.5$ & $82.7 \pm 13.8$ & $86.7 \pm 17$ \\
\hline Social interaction & $79.5 \pm 23.9$ & $80.4 \pm 25.5$ & $80 \pm 12.5$ & $80 \pm 17$ \\
\hline Sexual function & $55.7 \pm 36.4$ & $68.2 \pm 33.2$ & $83.3 \pm 28.9$ & $83.3 \pm 14.4$ \\
\hline Sleep & $63 \pm 16.9$ & $62 \pm 17.8$ & $73 \pm 14.1$ & $64.5 \pm 17.2$ \\
\hline Social support & $62.6 \pm 37.6$ & $69.1 \pm 24.8$ & $66.7 \pm 40.8$ & $57 \pm 46.2$ \\
\hline $\begin{array}{l}\text { Encouragement of dialysis } \\
\text { staff }\end{array}$ & $86.8 \pm 17.4$ & $91.2 \pm 14.5$ & $92.5 \pm 11.2$ & $65 \pm 41.8^{a}$ \\
\hline $\begin{array}{l}\text { Satisfaction with } \\
\text { treatment }\end{array}$ & $84.3 \pm 15$ & $81.4 \pm 17.6$ & $80 \pm 18.3$ & $83.3 \pm 20.4$ \\
\hline
\end{tabular}

Table 2: The SF-36 parameters scores at the beginning (T0) and at the end (T12) of the study for both the physical activity group (PA) and the control group (C).

\begin{tabular}{|c|c|c|c|c|}
\hline & \multicolumn{2}{|c|}{ PA } & \multicolumn{2}{|c|}{ C } \\
\hline & TO & T12 & TO & T12 \\
\hline Physical functioning & $56.9 \pm 21.7$ & $53.1 \pm 21.8$ & $75 \pm 25.1$ & $30 \pm 28.9$ \\
\hline Physical role limitation & $41.1 \pm 42.3$ & $51.8 \pm 39.8$ & $65 \pm 33.5$ & $80 \pm 27.4$ \\
\hline $\begin{array}{c}\text { Emotional role } \\
\text { limitation }\end{array}$ & $56.2 \pm 43.4$ & $87.5 \pm 20.6 *$ & $80 \pm 18.3$ & $86.7 \pm 29.8$ \\
\hline Social functioning & $65.4 \pm 21$ & $75.7 \pm 21$ & $72.5 \pm 25.6$ & $80 \pm 14.2$ \\
\hline Emotional well-being & $68.7 \pm 18.1$ & $70.6 \pm 16.2$ & $72 \pm 21.3$ & $73.6 \pm 17.6$ \\
\hline Bodily pain & $61.8 \pm 20.1$ & $63.8 \pm 21.2$ & $58 \pm 18.6$ & $64.5 \pm 14.3$ \\
\hline Vitality & $49.4 \pm 19.7$ & $53.5 \pm 17.7$ & $62.5 \pm 14.4$ & $57.5 \pm 9.6$ \\
\hline $\begin{array}{l}\text { General health } \\
\text { perception }\end{array}$ & $50.2 \pm 17.6$ & $51.6 \pm 19$ & $66.2 \pm 6.4$ & $62.5 \pm 6.1$ \\
\hline $0<0.05$ between $\mathrm{T0} a$ & 0 s & dor d aro & & \\
\hline
\end{tabular}


For the PA group and the $\mathrm{C}$ group, the scores of the 8 parameters of the SF-36 questionnaire presented no significant differences between the beginning and the end of the study.

Moreover, no significant differences were observed between the two groups.

\section{Biological parameters}

The results of biological parameters are presented in the table 3.

The different biological parameters presented no significant inter or intra-group differences whatever the measurement period.

\section{Sleep}

The results of the Epworth scale and the International restless legs syndrome study group scale are presented in the table 4.

The two scales presented no significant inter or intragroup differences whatever the measurement period.

\section{Discussion}

Our results showed an upward trend in the quality of life and a significant improvement in some parameters after the 12-week intradialytic resistance training program. Concerning the biological parameters and the sleep no significant results were observed.

\section{Quality of life}

The results of the KDQOL-SF questionnaire, and the two parts KDQOL and SF-36, showed no significant improvement after 12 weeks intradialytic training program. Our results were similar to those of Tawney, et al. [20] and Parsons [21]. Tawney, et al., observed the effects of a resistance training program and flexibility during 6 months on 39 hemodialysis patients. Whereas Parson, et al., observed the effects of a 24 session aerobic training program on 6 patients. The majority

Table 3: The biological parameters results at the beginning (T0) and at the end (T12) of the study for both the physical activity group (PA) and the control group (C).

\begin{tabular}{|c|c|c|c|c|}
\hline & \multicolumn{2}{|c|}{ PA } & \multicolumn{2}{c|}{ C } \\
\hline Kt/V & $1.23 \pm 0.34$ & $1.3 \pm 0.33$ & $1.11 \pm 0.21$ & $1.12 \pm 0.48$ \\
\hline Urea (g/L) & $1.26 \pm 0.38$ & $1.35 \pm 0.26$ & $1.35 \pm 0.22$ & $1.47 \pm 0.43$ \\
\hline Creatine (mg/L) & $78.29 \pm 27.64$ & $80.17 \pm 21.78$ & $79.26 \pm 22.22$ & $78.08 \pm 24.02$ \\
\hline CRP (mg/L) & $7.46 \pm 6.58$ & $6.62 \pm 5.69$ & $6.67 \pm 3.6$ & $4.97 \pm 1.99$ \\
\hline Albumin (g/L) & $41.25 \pm 2.79$ & $41.08 \pm 2.76$ & $41.95 \pm 3.36$ & $41.72 \pm 4.46$ \\
\hline
\end{tabular}

Table 4: The Epworth scale and the International restless legs syndrome study group scale scores at the beginning (T0) and at the end (T12) of the study for both the physical activity group (PA) and the control group (C).

\begin{tabular}{|c|c|c|c|c|}
\hline & \multicolumn{2}{|c|}{ PA } & \multicolumn{2}{c|}{ C } \\
\hline Epworth (score) & $5.14 \pm 4.13$ & $5.29 \pm 3.79$ & $5.75 \pm 3.77$ & $5.25 \pm 6.5$ \\
\hline IRLSSG (score) & $13.2 \pm 9.38$ & $10.2 \pm 9.28$ & $12 \pm 8.64$ & $16.25 \pm 4.19$ \\
\hline
\end{tabular}

of studies measuring the quality of life in hemodialysis patients with KDQOL-SF questionnaire have observed the different parameters of each part only (KDQOL and SF).

When we observe the KDQOL parameters only, the dialysis-related symptom score was better after the training program for the PA group. For the $\mathrm{C}$ group, the score concerning the adverse effect of kidney disease on lifestyle decreased significantly between the beginning and the end of the study. Few studies have involved the KDQOL-SF and, to our knowledge, one of these studies, carried out by Ling [22], observed a significant result on its parameters. In this study, the effects of a 3 month home-based aerobic training program (Taï-Chi) have been evaluated on 33 hemodialysis patients and they noticed an improvement in the score regarding the burden of the kidney disease. Therefore, we could hypothesize that an aerobic or a resistance training program is beneficial to the quality of life in kidney diseaserelated hemodialysis patients and a lack of physical exercise is responsible for a negative impact on daily life activities. A 3 month duration program seems sufficient to observe results but too few data are available to confirm this.

Concerning the SF-36 questionnaire, more data are available with regard to its parameters and its two parts; mental and physical components. With our resistance training program, the physical component score presented no significant difference between the beginning and the end of the study whereas the mental component score was significantly better after 12 weeks training program. Painter, et al. [23] observed contrary results; no difference for the mental component score and an increase in the physical component score. The authors evaluated the effects of a 16week program, on 180 hemodialysis patients, in two parts; the first part consisting of 8 weeks of home exercises and the second part consisting of 8 weeks of intradialytic cycling. Another study observed improvements in both the mental and the physical components after a 3-month intradialytic training program including lower extremity strength training and 30 min cycle ergometry on 18 hemodialysis patients [24]. We could hypothesize that a strength or resistance training program had some effects on the mental component and the aerobic training program with cycling had some effects on the physical component of the SF-36 questionnaire.

Considering the parameters of the SF-36 questionnaire, we observed a significant improvement in the PA group in the emotional role limitation score after our 12 week resistance program. However, no significant result was observed for the $\mathrm{C}$ group. Ling, et al. [22] who evaluated the effects of a 3 month home-based aerobic training program on 33 hemodialysis patients, observed an improvement in the emotional well- being, bodily pain and general health perception scores. In another study, a 16-week home-based aerobic training program during dialysis sessions completed by 180 patients, the authors noticed an improvement in the 
physical functioning, physical role limitation, bodily pain and general health perception scores [23]. Tawney, et al. [20] evaluated the effects of their Life Readiness Program (increase in daily life activities and strength and flexibility exercises) on 39 hemodialysis patients over a period of 6 months and they observed an improvement in the physical functioning score. It would seem that aerobic training is more favorable for an improvement in the general quality of life, measured by the SF-36. However, the low number of patients in our study, compared to the three others, may explain the few significant results to be found in ours.

Since the use of questionnaire is subjective, we should search other objective measurements of physical performance.

\section{Biological parameters}

The biological parameters (Kt/V, urea, creatine, C-Reactive Protein [CRP] and albumin), presented no significant differences whatever the group or the measured period. Our results were similar to those of Parsons, et al. [21] who carried out a study on 13 hemodialysis patients and evaluated the effects of a 5 month intradialytic aerobic exercise program on urea, creatine and albumin.

In our study, CRP was unchanged.

However, contradictory results on CRP level and physical activity in hemodialysis patients were observed. Indeed, some study observed no improvement in the CRP level [25] with a combined training program of strength and aerobic exercises on 5 patients over 16 weeks. The low number of patients and the short duration of their study may explain the lack of significant results concerning this parameter. These results were in accordance with ours but not with those of Cheema, et al. [7] nor Afshar, et al. [26]. In the first one, the effects of a 12 week intradialytic resistance training program was evaluated on 24 hemodialysis patients those. The authors observed an improvement in the CRP level following their program. Compared to our study, their patients performed exercises with weights. The difficulty of their program was probably of a higher level than ours. And in the second one, the effects of an 8 week intradialytic aerobic program was carried out on 14 patients and they observed a significant decrease in the CRP level after a period of 8 weeks.

With regard to the dialysis efficiency, Kt/V, no significant results were noticed whatever the group or the measured period. Our results were contrary to those of Parsons, et al. [21]. The authors observed a significant improvement in Kt/V at week 16 and week 20 of a 5 month aerobic training program completed by 13 hemodialysis patients. The type of exercise and the duration of their study could explain this difference between our results and theirs. Kong, etal. [27], also observed an increase in the Kt/V after one 60-minute aerobic exercise dialysis session completed by 11 hemodialysis patients. In this study again, the type of exercise was different from ours. Kong, et al. [27] noticed that exercise significantly reduced urea and creatine rebound. The reduction ratio for these solutes and $\mathrm{Kt} / \mathrm{V}$ were significantly greater in the dialyses with exercise as a result of their lower rebound. Vaithilingam et al. [28] evaluated the effect of one week of intradialytic aerobic exercise on 12 hemodialysis patients. They observed no changes in $\mathrm{Kt} / \mathrm{V}$ when exercise was performed during dialysis session. Same result was noted during an 8 week intradialytic aerobic exercise program completed by 6 hemodialysis patients [29].

It is well know that an increase of the urea concentration is observed due to the renal failure. Moreover, the urea concentration could increase too due to the possible dehydration occurs after the practice of physical activity. Parsons, et al. [21] observed a greater urea removal in the hemodialysis patients who performed the exercise compared to the control group. In our study, no measures of solute concentration in blood were performed along the dialysis run, so we can't conclude on this point.

\section{Sleep}

In our study, no significant results were observed regarding the two sleep scales used. To our knowledge, some studies have focused on the quality of sleep, but few studies have used the Epworth scale or, in particular, the International Restless Legs Syndrome Study Group scale (IRLSSG). Indeed, in their study, Afshar, et al. [26] evaluated the effect of an 8 week aerobic exercise program on 17 patients and observed an improvement in the sleep score. However, the questionnaire used and the type of exercise performed were different from those used in our study. Anand, et al. [31] observed that patients with a better score in the self-reported questionnaire activity had lower symptoms of insomnia and restless legs syndrome. Giannaki, et al. [31] evaluated the effect of a 6 month intradialytic aerobic training program on 15 hemodialysis patients and used the same two questionnaires as ourselves. They observed an improvement in the IRSLLG scale after a period of 6 months but no significant results in the Epworth scale. The duration and the type of exercise were different from our study, which could explain the different results for the IRSLLG scale. Concerning the Epworth scale however, these parameters had no apparent influence.

\section{Conclusion and Limits}

With our 12 week intradialytic resistance training program, some parameters showed a trend toward improved quality of life and decreased inflammatory process. However, there was no improvement in the quality of sleep whatever the duration or the type of exercise; be it aerobic or resistance. The effects observed on the parameters differed depending on the type of the exercise. 
Our results are consistent with the general effects of physical activity. There is no doubt that exercise improved patient well-being and mood and reduced disease-related stress. In consequence, the quality of life seems better.

\section{Acknowledgment}

We thank the CHR of Orléans, France, for its hospitality and the students who participated in the study, Blandine Torris, Kévin Dumas and Cédric Le Jean.

\section{References}

1. O'Hare AM, Tawney K, Bacchetti P, Johansen KL. Decreased survival among sedentary patients undergoing dialysis: results from the dialysis morbidity and mortality study wave 2. Am J Kidney Dis. 2003; 41: 447-454.

PubMed: https://www.ncbi.nlm.nih.gov/pubmed/12552509

2. Blumberg A, Nelp WB, Hegstrom RM, Scribner BH. Extracellular volume in patients with chronic renal disease treated for hypertension by sodium restriction. Lancet. 1967: 69-73.

PubMed: https://www.ncbi.nlm.nih.gov/pubmed/4165465

3. Finkelstein FO, Wuerth $\mathrm{D}$, Finkelstein $\mathrm{SH}$. Health related quality of life and the CKD patient: challenges for the nephrology community. Kidney Int. 2009; 76: 946-952.

PubMed: https://www.ncbi.nlm.nih.gov/pubmed/19675529

4. Johansen KL, Chertow GM, Kutner NG, Dalrymple LS, Grimes BA, et al. Low level of self-reported physical activity in ambulatory patients new to dialysis. Kidney Int. 2010; 78: 1164-1170.

PubMed: https://www.ncbi.nlm.nih.gov/pubmed/20811334

5. Perlman RL, Finkelstein FO, Liu L, Roys $E$, Kiser $M$, et al. Quality of life in chronic kidney disease: a cross-sectional analysis of the Renal Research Institute CKD study. Am J Kidney Dis. 2005; 45: 658-666. PubMed: https://www.ncbi.nlm.nih.gov/pubmed/15806468

6. Murtagh FE, Addington-Hall J, Higginson IJ. The prevalence of symptoms in end (stage renal disease: a systematic review. Adv Chronic Kidney Dis. 2007; 1: 82-99.

PubMed: https://www.ncbi.nlm.nih.gov/pubmed/17200048

7. Cheema B, Abas H, Smith B, O'Sullivan A, Chan M, et al. Progressive Exercise for Anabolism in Kidney Disease (PEAK): A Randomized, Controlled Trial of Resistance Training during Hemodialysis. J Am Soc Nephrol. 2007; 18: 1594-1601.

PubMed: https://www.ncbi.nlm.nih.gov/pubmed/17409306

8. Pearson TA, Mensah GA, Alexander RW, Anderson JL, Cannon RO 3rd, et al. Markers of inflammation and cardiovascular disease: application to clinical and public health practice: a statement for healthcare professionals from the Centers for Disease Control and Prevention and the American Heart Association. Circulation. 2003; 107: 499-511. PubMed: https://www.ncbi.nlm.nih.gov/pubmed/12551878

9. Anand S, Chertow GM, Johansen KL, Grimes B, Kurella Tamura M, et al. Association of self-reported physical activity with laboratory markers of nutrition and inflammation: the comprehensive dialysis study. J Renal Nutr. 2001; 21: 429-437.

PubMed: https://www.ncbi.nlm.nih.gov/pubmed/21239185

10. Heiwe S, Jacobson SH. Exercise Training in Adults With CKD: A Systematic Review and Meta-analysis. Am J Kidney Dis. 2014; 64: 383-393. PubMed: https://www.ncbi.nlm.nih.gov/pubmed/24913219

11. Daul $A E$, Schäfers RF, Daul K, Philipp T. Exercise during hemodialysis. Clin Nephrol. 2004; 61: 26-30.

PubMed: https://www.ncbi.nlm.nih.gov/pubmed/15233244
12. Painter P. Determinants of exercise capacity in CKD patients treated with hemodialysis. Adv in Chronic Kidney Dis. 2009; 16: 437-448. PubMed: https://www.ncbi.nlm.nih.gov/pubmed/19801134

13. Bullani R, El-Housseini $Y$, Giordano $F$, Larcinese A, Ciutto $L$, et al. Effect of intradialytic resistance band exercise on physical function in patients on maintenance hemodialysis: A pilot study. J Renal Nutr. 2011; 21:61-65.

PubMed: https://www.ncbi.nlm.nih.gov/pubmed/21195922

14. Borg G. Psychophysical bases of perceived exertion. Med Sci Sports Exerc. 1982; 14: 377-381.

PubMed: https://www.ncbi.nlm.nih.gov/pubmed/7154893

15. Hays RD, Kallich JD, Mapes DL, Coons SJ, Carter WB. Development of the kidney disease quality of life (KDQOL) instrument. Qual Life Res. 1994; 3: 329-338.

PubMed: https://www.ncbi.nlm.nih.gov/pubmed/7841967

16. Leplège A, Ecosse E, Pouchot J. Le questionnaire MOS SF-36: manuel de l'utilisateur et guide d'interprétation des scores, Estem. 2001.

17. Lean ME, Han TS, Seidell JC. Impairment of health and quality of life using new US Federal Guidelines for the identification of obesity. Arch Intern Med. 1999; 159: 837-843.

PubMed: https://www.ncbi.nlm.nih.gov/pubmed/10219929

18. Johns MW. A new method for measuring daytime sleepiness: The Epworth Sleepiness Scale. Sleep. 1991; 14: 540-545. PubMed: https://www.ncbi.nlm.nih.gov/pubmed/1798888

19. Walters AS, LeBrocq C, Dhar A, Hening W, Rosen R, et al. Validation of the International Restless Legs Syndrome Study Group rating scale for restless legs syndrome. Sleep Med. 2003; 4: 121-132.

PubMed: https://www.ncbi.nlm.nih.gov/pubmed/14592342

20. Tawney KW, Tawney PJ, Hladik G, Hogan SL, Falk RJ, et al. The life readiness program: A physical rehabilitation program for patients on hemodialysis. Am J Kidney Dis. 2000; 36: 581-591. PubMed: https://www.ncbi.nlm.nih.gov/pubmed/10977791

21. Parsons T1, Toffelmire EB, King-VanVlack CE. Exercise training during hemodialysis improves dialysis efficacy and physical performance. Arch Physical Med Rehab. 2006; 87: 680-687.

PubMed: https://www.ncbi.nlm.nih.gov/pubmed/16635631

22. Ling KW, Wong FS, Chan WK, Chan SY, Chan EP, et al. Effect of a home exercise program based on Tai Chi in patients with end-stage renal disease. Perit Dials Int. 2003; 23: 99-103.

PubMed: https://www.ncbi.nlm.nih.gov/pubmed/17986569

23. Painter P, Carlson L, Carey S, Paul SM, Myll J. Physical functioning and health-related quality-of-life changes with exercise training in hemodialysis patients. Am J Kidney Dis. 2000; 35: 482-492. PubMed: https://www.ncbi.nlm.nih.gov/pubmed/10692275

24. Oh-Park M, Fast A, Gopal S, Lynn R, Frei G, et al. Exercise for the dialyzed: aerobic and strength training during hemodialysis. Am J Phys Med Rehabil/Association of Academic Physiatrists. 2002; 81: 814-821. PubMed: https://www.ncbi.nlm.nih.gov/pubmed/12394992

25. Oliveros RMS, Avendano M, Bunout D, Hirsch S, De La Maza MP, et al. Estudio piloto sobre entrenamiento fisico durante hemodialisis. Rev Med Chile. 2011; 139: 1046-1053.

26. Afshar R, Emany A, Saremi A, Shavandi N, Sanavi S. Effects of intradialytic aerobic training on sleep quality in hemodialysis patients. Iran J Kidney Dis. 2011; 5: 119-123.

PubMed: https://www.ncbi.nlm.nih.gov/pubmed/21368391

27. Kong $\mathrm{CH}$, Tattersall JE, Greenwood RN, Farrington K. The effect of exercise during haemodialysis on solute removal. Nephrol Dial Transplant. 1999; 14: 2927-2931.

PubMed: https://www.ncbi.nlm.nih.gov/pubmed/10570099 
28. Vaithilingam I, Polkinghorne KR, Atkins RC, Kerr PG. Time and exercise improve phosphate removal in hemodialysis patients. Am J Kidney Dis. 2004; 43: 85-89.

PubMed: https://www.ncbi.nlm.nih.gov/pubmed/14712431

29. Parsons TL, Toffelmire EB, King-VanVlack CE. The effect of an exercise program during hemodialysis on dialysis efficacy, blood pressure and quality of life in end-stage renal disease patients. Clin Nephrol. 2004; 61: 261-274.

PubMed: https://www.ncbi.nlm.nih.gov/pubmed/15125032

30. Anand S, Johansen KL, Grimes B, Kaysen GA, Dalrymple LS, et al.
Physical acidity and self-reported symptoms of insomnia, restless legs syndrome, and depression: The comprehensive dialysis study: Physical activity, insomnia, RLS, and depression. Hemodial Int. 2013; 17: 50-58.

PubMed: https://www.ncbi.nlm.nih.gov/pubmed/22812496

31. Giannaki CD, Sakkas GK, Karatzaferi C, Hadjigeorgiou GM, Lavdas E, et al. Effect of exercise training and dopamine agonists in patients with uremic restless legs syndrome: a six-month randomized, partially double-bling, placebo-controlled comparative study. MBC Nephrol. 2013; 14: 194-205.

PubMed: https://www.ncbi.nlm.nih.gov/pubmed/24024727 